\title{
Laparoscopic vs. open inguinal hernia repair: A systematic review of literature
}

\author{
S.K. Jain ${ }^{1}$, Amit Gupta ${ }^{2}$, Sunil Kumar', R.C.M. Kaza ${ }^{1}$ \\ ${ }^{1}$ Department of Surgery, MAMC, New Delhi, ${ }^{2}$ Department of Surgery, UCMS \& GTB Hospital, New Delhi
}

\section{A B S T R A C T}

Inguinal hernia repair using mesh is one of the most frequently performed operations in general surgery. The mesh can be placed using an open technique or by laparoscopic approach. Many studies have highlighted the merits and risks of laparoscopic approach for the repair of inguinal hernia, the final sentence still remains to be written as majority of trials are too small to show clear benefits of one technique over another. To compare laparoscopic mesh repair with open method in management of inguinal hernia.
Access this article online

Website:

http://nepjol.info/index.php/AJMS

Key words: Search strategy PUBMED, MEDLINE, EMBASE, The Cochrane Central Controlled Trials \& NICE

\section{INTRODUCTION}

Inguinal hernia was repaired laparoscopically soon after the establishment of laparoscopic cholecystectomy as gold standard for cholelithiasis. However unlike laparoscopic cholecystectomy, which was very quickly accepted by the surgical community, laparoscopic hernia repair has remained a contentious issue since its inception. The early laparoscopic techniques of plugging the internal ring with mesh or simply closing the ring with staples were surgically unsound and were quickly abandoned when early trends showed a high recurrence rate. The later technique of reinforcing the inguinal floor with a mesh placed preperitoneally was based on the open procedure introduced by Stoppa. This laparoscopic method of tension-free mesh repair appeared to be gaining in popularity in the early 1990s among the enthusiasts. Early uncontrolled studies claimed that laparoscopic repair was superior to the conventional open repairs regarding postoperative pain, resumption of normal activities, and return to work. In 1984, Lichtenstein et al coined the term "Tension-Free Hernioplasty" and broke the convention by advocating routine use of mesh for hernia repair, thereby making tissue repair a thing of the past. Real controversy started in 1990, when laparoscopic Tension-Free repair came in to vogue and was routinely advocated and aggressively marketed by promising less pain and shorter recovery period, but the things in the small prints were completely ignored.

\section{How to decide which approach is better?}

The most scientific way to come to conclusion over superiority of one method over other is on the basis of evidence-based medicine. The best evidences are in the form of Meta-analysis or randomized controlled trials. Oranges cannot be compared with apples; similarly laparoscopic mesh repair cannot be compared with open tissue repair. So it has to be comparison between laparoscopic mesh repair and open mesh repairs. Few of the initial trials $\left(\mathrm{Liem}^{1}\right.$, Stoker ${ }^{2}$, and Grant $\left.{ }^{3}\right)$ compared laparoscopic mesh repair with open tissue repair and came to conclusions, which are not valid.

\section{METHODS \& MATERIAL}

\section{Objective}

The purpose of this review was to compare laparoscopic mesh techniques with open technique for inguinal hernia repair.

\section{Criteria for inclusion}

All published randomized controlled trial, meta-analysis \& NICE guidelines comparing laparoscopic inguinal hernia 
repair with open inguinal hernia repair were eligible for inclusion. Trials were included irrespective of the language in which they were reported.

\section{Types of participants}

The trials included all patients with a diagnosis of inguinal hernia for whom mesh repair was judged appropriate. Wherever possible, individual patient data from randomized patients were included in the systematic review.

\section{Types of interventions}

Methods of surgical repair of inguinal hernia:

a) Laparoscopic inguinal hernioplasty using mesh (including the trans-abdominal pre-peritoneal technique (TAPP) and the totally extra peritoneal technique (TEP)).

b) Open mesh repair using tension free hernioplasty.

\section{Types of outcome measures}

The following data items were sought for all trials:

1. Duration of operation (min)

2. Vascular injury

3. Visceral injury

4. Length of hospital stay (Days)

5. Time to return to usual activities (Days)

6. Time to return to work(Days)

7. Post operative pain

8. Chronic Persisting inguinal pain (defined as inguinal pain of any severity as near 12 months after the operation as possible provided this was at least after 3 months)

9. Hernia recurrence

10. Cost effectiveness

11. Learning curve

12. Quality of life

13. Day care surgery

\section{Search methods for identification of studies}

A database search for randomized controlled trials was conducted using MEDLINE, EMBASE, and The Cochrane Central Controlled Trials Registry.

We have analyzed the available data and randomized controlled trials comparing laparoscopic mesh repair versus open mesh repair of inguinal hernia. We did not analyze those trials, which compared lap mesh repair and open tissue repair, because there would be inherent superiority of lap mesh repair in the form of low recurrence rate by virtue of placement of mesh. Available literature was analyzed with regards to: recurrence rate, complications, operating time, cost effectiveness, post operative pain and return to work and activity.

\section{RESULTS}

\section{Recurrence rate}

An ideal approach to hernia repairs should have a low recurrence rate. Recurrence rates in various series are shown in Table 1. VA trial ${ }^{4}$ concluded in 2004 involving 2164 patients in 14 centers in USA measured recurrence of hernia at two years as the primary outcome. Recurrence was found to be $10.1 \%$ in the laparoscopic group and $4.1 \%$ for open group in the repair of primary inguinal hernias, but rates of recurrence were similar is two groups after repair of recurrent hernias (10\% and $14.1 \%$ respectively). MRC 5 laparoscopic hernia trial group found $1.9 \%$ recurrence rate in laparoscopic group and zero percent recurrence rates in open group at one year. This study involved 928 patients with inguinal hernias from 26 hospitals in UK and Ireland. Memon et $\mathrm{al}^{6}$ found a trend towards an increase in the relative odds of short-term recurrence of $50 \%$ after laparoscopic repair compared with open repair. Champault et $\mathrm{al}^{7}$ found recurrence rate of $6 \%$ in laparoscopic group versus $3 \%$ in open group in a series of 100 patients in a randomized trial. In a technology appraisal guidance 83 published by $\mathrm{NICE}^{8}$, UK in 2004, showed recurrence rate of $2.3 \%$ after TEP repair and $1.3 \%$ after open repairs.

\section{Complications}

As all studies indicate the recurrence in groin hernia surgery is a multifocal etiology as it is associated with the type of approach, prosthetic mesh, suture material, patient related issues eg. Chronic cough, constipation in post operative period or co existing morbid conditions etc. Incidence of serious visceral and vascular complications was found to be higher in laparoscopic group in most of the studies and randomized controlled trials comparing laparoscopic versus open mesh repair.Incidence of complications after laparoscopic inguinal hernia repairs can be seen in Table 2 .

\section{Inguinal hernia}

As evident from Table 2, incidence of complications is significantly higher in laparoscopic group. Incidence of vascular and visceral injuries was found to be higher after laparoscopic repair $(0.79 \%$ after lap repair versus $0 \%$ after open repair in NICE paper). IN MRC hernia trial group, all

\begin{tabular}{|c|c|c|}
\hline First Author & Laparoscopic & Open \\
\hline $\begin{array}{l}\text { MRC Lap } \\
\text { Groin Hernia } \\
\text { Trial group }\end{array}$ & $1.9 \%$ & $0 \%$ \\
\hline Champault $^{6}$ & $6 \%$ & $2 \&$ \\
\hline Neumayar ${ }^{4}$ & $10.1 \%$ & $4.9 \%$ \\
\hline NICE $2004^{7}$ & $2.3 \%$ & $1.3 \%$ \\
\hline Andersson ${ }^{21}$ & $2.5 \%$ & $0 \%$ \\
\hline
\end{tabular}




\begin{tabular}{|c|c|c|}
\hline First Author & Laparoscopic & Open \\
\hline $\mathrm{MC}$ & $8 / 2315$ & $1 / 2599$ \\
\hline Cormack $^{22}$ & $\begin{array}{l}\text { visceral } \\
7 / 2498 \\
\text { vascular }\end{array}$ & $\begin{array}{l}\text { visceral } \\
5 / 2758 \\
\text { vascular }\end{array}$ \\
\hline Grant $^{3}$ & $\begin{array}{l}15 \text { serious } \\
\text { complications }\end{array}$ & $\begin{array}{l}4 \text { serious } \\
\text { complications }\end{array}$ \\
\hline $\begin{array}{l}\text { MRC Trial } \\
\text { group } 5\end{array}$ & $5.6 \%$ & $1.4 \%$ \\
\hline Neumayer ${ }^{4}$ & $39 \%$ & $33.4 \%$ \\
\hline
\end{tabular}

serious complications occurred in the laparoscopic group. In VA trial, complication rate was 39.1\% in lap group including 2 deaths but $33.4 \%$ in open group. In an extensive review by Cochrane group in conjunction with European Hernia trialist group ${ }^{11}$, found serious vascular and visceral injuries more often in laparoscopic group (visceral injuries 8:2315 and vascular injuries 7:2498). A higher rate of postoperative urinary retention was found in the TEP group (6.3\%) than in the open group $(1.7 \%)$ ( $P 0.03)$. This complication was successfully managed by urinary catheterization during the night in a randomised controlled trial by Vidovic et al. ${ }^{12}$ In a met analysis by Schmidt et al in 2005 involving 34 trials the incidence of urinary bladder injuries in laparoscopic repairs was significantly higher at $0.1 \%$ versus zero after open mesh repairs. Also, the overall incidence of vascular injury during laparoscopic repairs was $0.09 \%$ as against no reported cases during open operations. ${ }^{12}$

\section{Operating time}

Laparoscopic inguinal hernia repair takes longer than open mesh repair. In technology appraisal guidance 83 by National Institute for clinical excellence, Sept. 2004, it was stated that laparoscopic surgery was associated with a statistically significant increase in operation time compared with open methods of hernia repair. Meta-analysis of 16 randomized control trials of Trans abdominal pre peritoneal (TAPP) repair demonstrated on overall increase of 13.33 minutes compared with open repair. Meta-analysis of eight randomized control trial of trans extraperitoneal (TEP) repair demonstrated an overall increase of 7.89 minutes compared with open repair. Memon and colleagues reviewed the data from 29 published randomized clinical trials and concluded that patients who underwent laparoscopic repair of inguinal hernia took longer time for surgery. In a Bringman ${ }^{13}$ trial operating time was found to be 5 minutes shorter in open mesh repair in comparison to laparoscopic group. The average time taken for TAPP/TEP (65.7 min) was significantly longer than that for the Lichtenstein repair (55.5 min) in a metanalysis published by Schmidt et $\mathrm{al}^{14}$ in 2005 involving 34 trials (Table 3).

\begin{tabular}{|c|c|c|}
\hline First Author & Laparoscopic & Open \\
\hline $\mathrm{MC}$ & 14.8 minute & \\
\hline Cormack 22 & longer $(p<0.0001)$ & \\
\hline Memon $^{8}$ & $\begin{array}{l}15.2 \text { minute } \\
\text { longer }(p<0.0001)\end{array}$ & \\
\hline $\begin{array}{l}\text { MRC Trial } \\
\text { group }^{5}\end{array}$ & 58.4 minute & 43.3 minute \\
\hline Bringman $^{9}$ & 50 minute & 45 minute \\
\hline $\mathrm{Picchio}^{23}$ & 49.6 minute & 33.9 minute \\
\hline Chung ${ }^{24}$ & $\begin{array}{l}\text { Laparoscopic } \\
\text { longer in all } \\
\text { groups }\end{array}$ & \\
\hline Wright ${ }^{25}$ & 58 minutes & 45 minutes \\
\hline
\end{tabular}

Time to return to normal activity

Majority of patients are able to perform normal activities at one week whether after open or laparoscopic surgery. Data regarding time to return to activity are rather subjective. Type of employment or profession, to which patient is returning will influence how long he needs to be away from work. Patient who is doing desk job in office will return to work earlier than a patent with a job that entails heavy lifting. Some patients will be getting paid sick leave, so they will have less incentive to go back to work early. Time to return to daily activities was found to be one day shorter for laparoscopic group than those undergoing open repair of hernia in a VA hernia trial group, but the time to resumption of sexual activity was similar in the two groups. However at 3 months of follow up, there was no difference in the activity level between the laparoscopic and open group. Lawrence et $\mathrm{al}^{18}$ did not find any significant difference in return to normal activities in two groups.

\section{Cost effectiveness}

Technology appraisal paper 83 by NICE in Sept. 2004 concluded that laparoscopic inguinal repairs was associated with an increased cost of between 100-400 sterling pounds per procedure. Open pre-peritoneal method was found to be most cost effective method of open repair. Hospital stay was shortest with this method of repair. Laparoscopic hernia repair in UK has additional cost of 300 pounds over open repair, because of more operating time, time in hospital and use of specialized equipments and obligatory need for general anaesthesia. The argument that the additional cost of lap hernia is offset by can earlier return of activity has been questioned. A recent analysis concluded that laparoscopic repair was not cost effective in terms of cost per recurrence avoided. In a recent study by Jacobs et $\mathrm{al}^{23}$ which compared institutional costs in laparoscopic TEP versus open repair of inguinal hernia, procedure related cost to the hospital was found to be higher for laparoscopic repair(USD 237) in comparison to open repair (USD_117) but still laparoscopic repair was economical to hospital because of higher rate of reimbursement for laparoscopic repair by insurance companies (Table 4). 


\begin{tabular}{|c|c|c|}
\hline First Author & Laparoscopic & Open \\
\hline $\begin{array}{l}\text { MRC Trial } \\
\text { group }^{5}\end{array}$ & $\begin{array}{l}314 \text { more } \\
\text { pound }\end{array}$ & \\
\hline Anderson ${ }^{21}$ & $\$ 1091$ higher & \\
\hline Jhoansson ${ }^{26}$ & 7063SEK & 417 SEK \\
\hline Wellwood 27 & $\$ 505$ more & \\
\hline Heikkine ${ }^{28}$ & $\$ 446$ more & \\
\hline
\end{tabular}

\section{Learning curve of laparoscopic repair}

Laparoscopic inguinal hernia repair is a more complex procedure with a steeper learning curve than open repair. It requires different skills and a familiarity with preperitoneal anatomy. Two large series concluded that 250-300 cases are required to achieve expertise. This figure is hard to achieve with current surgical programmes. Jacob et al suggested that laparoscopic hernia repair should only be carried out in specialist centers. All most all studies have concluded that laparoscopic hernia repair should be carried out by a surgeon who has a specialized training in performing this procedure.

\section{Day care surgery}

Open inguinal hernia can be performed as a day care procedure. Day surgery provides a high quality, patientcentered treatment that is safe, efficient and effective and is accompanied by a lower incidence of hospital acquired infection and early return to normal activity compared with in-patient treatment. In an randomized control trial conducted by Lau et $\mathrm{al}^{24}$ in 2006 showed that Day-case TEP was superior to open Lichtenstein hernioplasty for the repair of unilateral primary inguinal hernia in males. The benefits of day-case TEP included less postoperative pain, a faster return to work, and a lower incidence of chronic inguinal pain. ${ }^{25}$ However only very few studies support laparoscopic inguinal hernia repair as day care surgery.

\section{Post operative pain}

Post operative pain was found to be less in laparoscopic hernia repair group across the board. ${ }^{26} \mathrm{VA}$ group did not find any difference in post operative pain after 14 days. Stoker et al found less post operative pain for the first 4 hours after open hernia repair probably due to effect of local anaesthesia. The proportion of patients with reported testicular pain was higher in the TEP group $(\mathrm{P}=.003)$ in a study reported by Hallan et $\mathrm{al}^{27}$ in a randomised control trial comparing TEP with open mesh inguinal repair but permanent impaired inguinal sensibility was more common in the open group $(\mathrm{P}=.004)$

\section{Quality of life}

Quality of life measured in terms of post operative pain, quick return to normal activity physical role, general health \& emotional role was found to be significantly better in TEP repair in comparison to open mesh repair in a recently published randomized control trial by Myers et $\mathrm{al}^{28}$
Till date no clear cut scientific data is there in published literature which reflects incidence/etiology of sexual dysfunction after groin hernia surgery. However in some of the patients it may be purely psychic or due to chronic inguinodynia they may experience some difficulty in sexual intercourse.

An updated NICE guideline on laparoscopic hernia repair in September 2004 recommends

1. For primary unilateral inguinal hernia patient should be given a choice of open and laparoscopic repair.

2. Laparoscopic hernia repair should be performed only by properly trained surgeons.

3. Patients should be informed about TAPP and TEP repair and their risks so, they choose an appropriate procedure.

4. For repair of recurrent and bilateral inguinal hernia, laparoscopic repair should be considered.

5. When laparoscopic surgery is undertaken for inguinal hernia, the totally extraperitoneal (TEP) procedure should be preferred.

\section{CONCLUSION}

Laparoscopic hernia repair is more costly; difficult to learn with a steep learning curve, carries the risk of serious visceral and or vascular injuries. ${ }^{29}$ Recurrence rates for endoscopic techniques are generally underestimated because most studies are either not prospective or do not include long-term follow-up evaluation. ${ }^{30,31}$ All cases of inguinal hernia are not suitable for laparoscopic hernia repair as it is contraindicated in strangulated hernia, sliding hernia, irreducible hernia, and patients who are elderly or have co-morbid conditions. Laparoscopic hernia repair cannot be performed as day care ${ }^{32}$ surgery or under local anesthesia. Open mesh repair is economical, easy to teach and learn without any steep learning curve. ${ }^{33}$ Open hernia repair does not need any specialized training and results are some in both specialist and non-specialist center. ${ }^{34}$ Open hernia repair does not carry any risk of serious visceral or bowel injuries. Open mesh repair is suitable for all types of inguinal hernias including strangulated, irreducible, sliding hernia or in elderly patients and patients with co-morbidity. ${ }^{35}$ Open inguinal hernia repair is ideal for day-care surgery, especially under local anesthesia. The final word on management of inguinal hernia is still to be written. In collecting, assimilating and distilling the wisdom of today we must provide a base from which further advances may be made.

\section{REFERENCES}

1. Liem MSL, van der Graaf $Y$ and van Steensel CJ. Comparison of conventional anterior surgery and laparoscopic surgery for inguinal - hernia repair. N Eng J Med 1997;336:1541-1547. 
2. Stoker DL, Spiegelhalter DJ, Singh R and Wellwood JM. Laparoscopic versus open inguinal hernia repair. Randomized prospective trial. Lancet 1994;343:1243-1245.

3. Grant A. Laparoscopic compared with open methods of inguinal hernia repair: Systematic review of randomized controlled trials. Br J Surg 2000;87:860-867.

4. Vale L, Grant A, McCormack K and Scott NW. EU Hernia trialist collaboration. Cost effectiveness of alternative methods of surgical repair of inguinal hernia. Int J Technol Assess Health Care 2004;20:192-200.

5. MRC Laparoscopic Inguinal Hernia Trial Group. Laparoscopic Versus open repair of inguinal hernia: A randomized comparison. Lancet 1999;354:185-190.

6. Memon MA, Cooper NJ, Memon B, Memon MI and Abrams KR. Meta analysis of randomized clinical trials comparing open and laparoscopic inguinal hernia repair. Br J Surg 2003;90:14791492.

7. Champault G, Rizk N, Catheline J, Turner R and Boutelier P. Inguinal hernia repair, totally preperitoneal laparoscopic approach versus Stoppa operation. Randomized trial of 100 cases. Surg Laparosc Endosc 1997;6:445-450.

8. Technology appraisal guidance 83. Laparoscopic surgery for Inguinal Hernia repair, issued by National Institute for clinical Excellence, UK. Issue date September 2004.

9. McCormack K and Scott NW. Laparoscopic techniques versus open techniques for inguinal hernia repair. Cochrane Database systems review. 2003;1:CD001785.

10. Neumayer L, Giobbe-Hurder A, Johansson O, et al. Open mesh versus laparoscopic mesh repair of inguinal hernia. N Eng J Med 2004; 350:1819-1827.

11. Neumayer L, Giobbe-Hurder A, Johansson O, Fitzgibbons R, Dunlop D, Gibbs J, et al. Open mesh versus laparoscopic mesh repair of inguinal hernia. N Eng J Med 2004; 350:1819-1827.

12. Vidovic D, Kirac I, Glavan E, Filipovic-Cugura J, Ledinsky $M$ and Bekavac-Beslin M. Laparoscopic Totally Extraperitoneal Hernia Repair Versus Open Lichtenstein Hernia Repair: Results and Complications. J Lap \& Ad Surg Techniques.17;2007:585-590.

13. Bringman $S$, Ramel $S$, Heikkinen $T$, Englund $T$, Westman $B$ and Anderberg $B$, et al. Tension free inguinal hernia repair. TEP versus mesh plug versus Lichtenstein (a prospective randomized clinical trial). Ann Surg 2003;237:142-147.

14. Schmedt CG, Sauerland S, and Bittner R. Comparison of endoscopic procedures vs Lichtenstein and other open mesh techniques for inguinal hernia repair: a meta-analysis of randomized controlled trials. Surg Endosc 2005;19:188-199.

15. Picchio M, Lombardi A and Zolovkins A. Tension free laparoscopic and open hernia repairs. Randomized controlled trial of early results. World J Surg 1999;23:1004-1009.

16. Chung RS and Rowland DY. Meta-analysis of randomized controlled trial of laparoscopic versus conventional inguinal hernia repairs. Surg Endosc 1999;13:689-694.

17. Wright DM, Kennedy A and Baxter JN. Early outcome after open versus extra peritoneal endoscopic tensions free hernioplasty. A randomized clinical trial. Ann Surg 1996;119:552-557.

18. Lawrence K, McWhinne D and Goodwin A. Randomized controlled trial of laparoscopic versus open repair of inguinal hernia. Early results. BMJ1995;311:981-985.

19. Andersson B, Hallen $M$ and Leveau P. Laparoscopic extra peritoneal inguinal hernia repair versus open mesh repair: $A$ prospective randomized controlled trial. Surgery 2003;133:464472.

20. Johansson B, Hallerback B and Glire H. Laparoscopic mesh versus open preperitoneal mesh versus conventional technique for inguinal hernia repairs (SCUR) hernia Repair study). Ann Surg 1999;230:225-231.

21. Wellwood J, Sculpher MJ and Stoker D. Randomized controlled trial of laparoscopic versus open mesh repair for inguinal hernia: outcome and cost. BMJ 1998;317(7151):103-110.

22. Heikkinen TJ, Haukipuro $K$ and Koivukangas $P$. A prospective randomized outcome and cost comparison of totally extra peritoneal endoscopic hernioplasty versus Lichtenstein hernia operation among employed patients. Surg Laparosc Endosc 1998;8(5):338-344.

23. Jacobs DO. Mesh repair of inguinal hernias - redux. N Eng $J$ Med 2004;350:1895-1897.

24. Jacobs VR and Morrison JE. Comparison of institutional costs for laparoscopic pre-peritoneal inguinal hernia versus open repair and its reimbursement in an ambulatory surgery center. Surg Laparosc Endosc Percutan Tech 2008;18(1):70-74.

25. Lau H, Patil NG and Yuen WK. Day-case endoscopic totally extra-peritoneal inguinal hernioplasty versus open Lichtenstein hernioplasty for unilateral primary inguinal hernia in malesA randomized trial. Surg Endosc (2006) 20:76-81.

26. Bruce J. Forewords. In Nyhus LM, Harkins HN (Eds): Hernia (1st edn). Philadelphia: Lippincott; 1964.

27. Montgomery A, Bergkvist L and Rudberg C. Chronic pain 5 years after randomized comparison of laparoscopic and Lichtenstein inguinal hernia repair. British Journal of Surgery 2010;97(4):600608.

28. Hallan M, Bergenfelz A and Westerdahl J. Laparoscopic extraperitoneal inguinal hernia repair versus open mesh repair:long-term follow-up of a randomized controlled trial. Surgery. 2008;143(3):313-317.

29. Myers E, Browene KM and Kavanagh DO. Laparoscopic (TEP) Versus Lichtenstein Inguinal Hernia Repair: A Comparison of Quality-of-Life Outcomes. World J Surg DOI 10.1007/s00268010-0730.

30. Kark AE, Kurzer M and Belsham P. Three thousand one hundred seventy five primary inguinal hernia repairs: advantage of ambulatory open mesh repair using local anaesthesia. J Am Coll Surg 1998; 186:447-456.

31. Bittner R, Schmedt CG and Schwartz J. Laparoscopic Tran peritoneal procedure for routine repair of inguinal hernia. $\mathrm{Br} \mathrm{J}$ Surg 2002;89:1062-1066.

32. Staarink M, van Veen RN, Hop WC and Weidema WF. A 10-year follow-up study on endoscopic total extraperitoneal repair of primary and recurrent inguinal hernia Surg Endosc 2008; 22:1803-1806.

33. Cooke T, Fitzpatrick R and Smith I. Achieving day surgery targets: a practical approach to warding improving efficiency in day care units in the UK London: Advance Medical Publications;2004.

34. Edwards CC and Railey RW. Laparoscopic hernia repair: the learning curve. Surg Laparosc Endosc Percut Tech 2000;10:149153.

35. Jain S and Norbu C. Is Laparoscopic Groin Hernia Repair Better Than Open Mesh Repair? Internet Journal Of Surgery 2005; 8(2).

\footnotetext{
Authors Contribution:

SKJ and AG - Prepared the draft and wrote the manuscript; SK and RCMK - Collected and analysed the data; AG - Final corrections and formatting
}

Source of Support: This study was financially supported by llam university of medical sciences, Conflict of Interest: None declared. 